\title{
GPS observations of coseis- mic deformation following the 2016, August 24, Mw 6 Amatrice earth- quake (central Italy): data, analysis and preliminary fault model
}

\author{
Cheloni D. *, Serpelloni E. *o, Devoti R. *, D'Agostino N.*, Pietrantonio G. *,

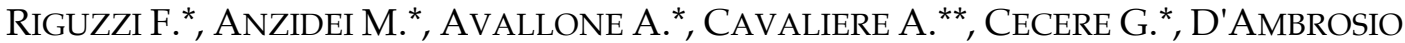

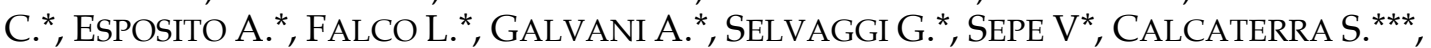 \\ GiUliani R. ${ }^{* * *}$, MATTONE M. ${ }^{* * *}$, GAMBINO P. ${ }^{* *}$, ABRUZZESE L. ${ }^{*}$, CARdinAlE V. ${ }^{*}$,

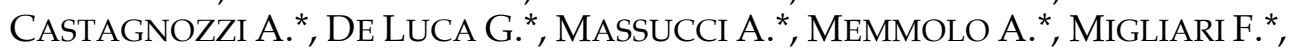 \\ MINICHIELLO F. ${ }^{*}$, ZARRILLI L. * \\ * Istituto Nazionale di Geofisica e Vulcanologia, Centro Nazionale Terremoti; \\ ** Istituto Nazionale di Geofisica e Vulcanologia, Sezione di Bologna; \\ *** ISPRA, Servizio Geofisica, Istituto Superiore per la Protezione e la Ricerca Ambientale, \\ Roma; \\ ${ }^{* * * *}$ Dipartimento Protezione Civile, Dipartimento Protezione Civile, Ufficio Rischio Sismico \\ e Vulcanico, Roma; \\ ○ Corresponding author: enrico.serpelloni@ingv.it
}

\begin{abstract}
We used continuous Global Positioning System (GPS) measurements to infer the fault geometry and the amount of coseismic slip associated to the August 24, 2016 Mw 6 Amatrice earthquake. We realized a three-dimensional coseismic displacement field by combining different geodetic solutions generated by three independent analyses of the raw GPS observations. The coseismic deformation field described in this work aims at representing a "consensus" solution that minimizes the systematic biases potentially present in the individual geodetic solutions. Because of the limited number of stations available we modeled the measured coseismic displacements using a uniform slip model, deriving the geometry and kinematics of the causative fault, finding good agreement between our geodetically derived fault plane and other seismological and geological observations.
\end{abstract}

\section{INTRODUCTION}

A Mw 6.0 (Ml 6.0) earthquake struck the Central Apennines between the towns of Norcia and Amatrice on August 24, 2016, at 03:36 (local time). The mainshock has been localized at longitude $13.234^{\circ} \mathrm{E}$ and lati- tude $42.698^{\circ} \mathrm{N}$, at a depth of $8.1 \mathrm{~km}$ (http://iside.rm.ingv.it). The aftershock sequence involved a crustal volume extending SE-NW for $\sim 30 \mathrm{~km}$ and down to $\sim 15 \mathrm{~km}$ of depth, including (up to October, 2016) one $\mathrm{Mw}$ 5.4 event and 14 events with $M \geq 4$ (http://iside.rm.ingv.it). The focal mecha- 
nisms of the mainshock and of the larger aftershocks (http://www.bo.ingv.it/RCMT and http:/ / cnt.rm.ingv.it/tdmt) consistently show a SW-NE oriented extension with chainparallel oriented nodal planes, in agreement with the SW-NE extension measured by GPS stations in this sector of the Apennines (e.g., Galvani et al., 2012 and references therein).

This earthquake occurred within the belt of high geodetic deformation rates that characterizes the Apennine chain (e.g., D'Agostino, 2014) and where several continuous Global Navigation Satellite System (GNSS) networks, managed by private and public companies and institutions, are operating. Figure 1 shows the (interseismic) horizontal GPS velocities with respect to stable Europe together with a chainnormal velocity cross section, where horizontal velocities are projected along the $\mathrm{N} 40^{\circ} \mathrm{E}$ direction, that is parallel to the direction of maximum geodetic extension. The velocity field shown in Figure 1 has been obtained from the combination of three different GPS velocity solutions (e.g., Avallone et al., 2010), realized using the BERNESE, GAMIT and GIPSY software. Figure 1 shows $\sim 4 \mathrm{~mm} / \mathrm{yr}$ of lengthening rate between Rieti and Ascoli Piceno, resulting in a strain-rate of $\sim 60$ nanostrain/yr. This kinematic feature is in agreement with other geological and seismotectonics information, and with the preliminary coseismic deformation observed by radar (InSAR) observations (Bignami et al., 2016) for the Amatrice earthquake.

In this work we describe the GPS data used to study the coseismic deformation related to the August 24 mainshock and provide a preliminary model of the coseismic source inverted from a "consensus" GPS coseismic displacement field, obtained following the procedures described in Devoti (2012) and used to study the 2012 Emilia seismic sequence (Serpelloni et al., 2012).

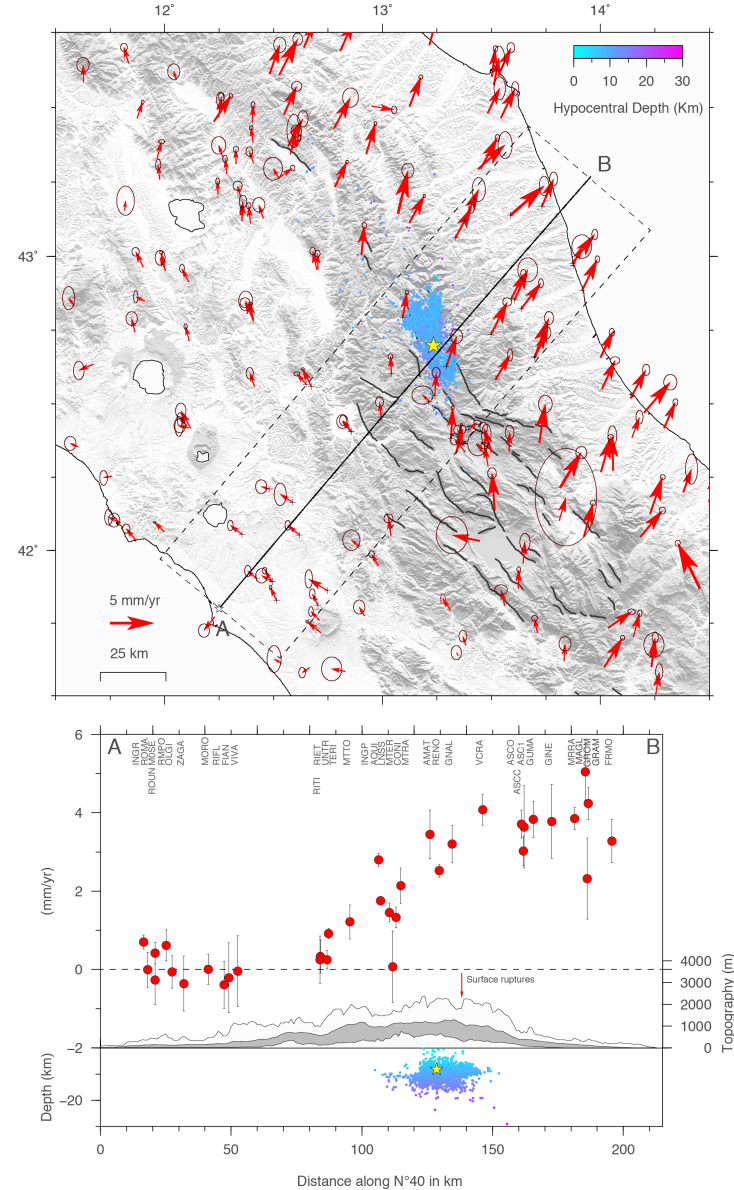

Figure 1. [Top] Interseismic horizontal velocities in the central Apennines (red arrows), with 95\% confidence errors (from Devoti et al., 2016). The yellow star shows the epicenter of the August 24, $M w 6$ mainshock, whereas the colored circles show the distribution of aftershocks occurred in the first week from http://iside.rm.ingv.it, colored as a function of depth. The dashed lines show the box of the $A-B$ cross-section, shown in the bottom panel. [Bottom] Cross section showing horizontal velocities components projected along the $N^{\circ} 40 E$ profile, with $1 \sigma$ uncertainties, together with the swath topographic profile, the mainshock (yellow star) and first week aftershocks (colored circles). The red arrow shows the position of surface breaks observed in the field by the INGV EMERGEO (http://emergeo.ingv.it/) working group (courtesy of S. Gori and E. Falcucci). 


\section{AVAILABLE GPS DATA}

Several continuous GPS (cGPS) stations, managed by different private and public institutions, were operating in and around the epicentral area, before and after the seismic sequence started on August 24, 2016. Figure 2 shows the distribution of cGPS stations, together with the first week of aftershocks. With the exclusion of the GPS station in Norcia (NRCI), all sites were continuously measuring across the mainshock. The first data for NRCI after the mainshock is relative to August 26. In the following hours and days, several GPS instruments have been installed at geodetic markers belonging to the CaGeoNet network (Anzidei et al., 2008; Galvani et al., 2012) and the first rapid solution has been integrated (see Figure 2) with data from continuous GPS networks managed by the Italian Civil Protection Department (DPC) and the Istituto Superiore per la Protezione e la Ricerca Ambientale (ISPRA). In particular, 7 sites of the CaGeoNet network have been re-occupied following the indications from a forward coseismic model implemented from the mainshock focal solution and selecting sites for which relatively longer time-series where available, in order to allow a rather robust estimate of the pre- (i.e., interseismic) seismic velocities. The data collected at these stations are, at the time of this publication, still under processing, and here we focus on the results provided by the continuous GPS stations. It is worth noting that many stations were collecting data at higher sampling rates than standard 30 seconds (from $1 \mathrm{~Hz}$ to $20 \mathrm{~Hz}$ sampling frequencies), and recorded the dynamic displacements related to the mainshock over a wider area in central Italy (Avallone et al., this issue).

\section{GPS DATA ANALYSIS}

The available GPS data, in the form of 24hours 30-seconds sampling, RINEX files, have been processed by three different GPS data analysis groups, using different software and analysis procedures, as in Serpelloni et al. (2012). In particular, GPS data have been analyzed using the BERNESE (http://www.bernese.unibe.ch), GAMIT (http:/ / www-gpsg.mit.edu/ simon/gtgk) and GIPSY (http://gipsy.jpl.nasa.gov/orms/goa) software. We refer to Avallone et al. (2010) and Serpelloni et al. (2012) for more detailed descriptions of the three processing approaches. In this work the three sets of coseismic displacements solutions have been obtained estimating offsets in the position time-series using up to 15 days before and three days after the August, 24 mainshock, respectively. The time series of stations displacements are provided at the following link: ftp:/ / gpsfree.gm.ingv.it/amatrice2016/static/ plots.

The combination of the individual solutions has been obtained by solving for the combined offsets (unknowns) in a least squares sense (see Devoti, 2012). The WRMS (weighted root mean squared) of the differences between the three solutions is of 1.6 and $3.3 \mathrm{~mm}$ in the horizontal and vertical components, respectively. The final coseismic displacement field can be considered as a "consensus" measurement and it is the result of a comparison and validation process with repeated feedback between the three different analysis centers. The comparison is done with the intention of comparing the different results and reducing sources of error associated with individual processing strategies. The iteration process assesses the robustness of each single GPS result, thus minimizing erroneous interpretations based on individual solutions. 
Table 1. Observed and modeled co-seismic displacements for the cGPS stations shown in Fig. 3, where E_obs, N_obs and Up_obs are the observed co-seismic displacements (in $\mathrm{mm}$ ) for the east, north and vertical components and SE_obs, SN_obs and Sup_obs are the uncertainties of the co-seismic displacements (in $\mathrm{mm}$ ) for the east, north and vertical components, respectively. E_mod, N_mod and Up_mod are the modeled coseismic displacements (in $\mathrm{mm}$ ). The table including all the stations analyzed is available at the following link:ftp://anonymous@gpsfree.gm.ingv.it/amatrice2016/static/gps_cos_mod.txt.

\begin{tabular}{|c|c|c|c|c|c|c|c|c|c|c|c|}
\hline STN & $\begin{array}{l}\text { E_obs } \\
(\mathbf{m m})\end{array}$ & $\begin{array}{c}\text { SE_obs } \\
(\mathrm{mm})\end{array}$ & $\begin{array}{c}\text { N_obs } \\
(\mathbf{m m})\end{array}$ & $\underset{(\mathrm{mm})}{\text { SN_obs }}$ & $\underset{\text { (mm) }}{\text { Up_obs }}$ & $\underset{(\mathrm{mm})}{\text { Sup_obs }}$ & $\underset{(\mathrm{mm})}{\text { E_mod }}$ & $\underset{(\mathrm{mm})}{\text { N_mod }}$ & $\underset{(\mathrm{mm})}{\text { Up_mod }}$ & $\begin{array}{l}\text { Lon } \\
\left({ }^{\circ} \mathrm{E}\right)\end{array}$ & $\begin{array}{l}\text { Lat } \\
\left({ }^{\circ} \mathbf{N}\right)\end{array}$ \\
\hline AMAT & -11.0156 & 1.0904 & 21.9345 & 1.1709 & -14.8495 & 4.4746 & $\begin{array}{c}- \\
12.3500\end{array}$ & 22.4500 & -11.4100 & 13.2924 & 42.6265 \\
\hline ASC1 & 14.5814 & 0.9515 & 6.2451 & 0.9864 & -0.6316 & 3.6641 & 10.9500 & 4.8100 & -0.2500 & 13.6061 & 42.8521 \\
\hline ASCC & 12.9191 & 0.8879 & 6.2370 & 1.0215 & -1.8462 & 3.6052 & 11.3700 & 5.2200 & -0.2200 & 13.5930 & 42.8573 \\
\hline GNAL & 5.9601 & 0.7159 & 0.1391 & 0.8175 & -1.2956 & 2.8290 & 4.3100 & -0.0500 & 2.0200 & 13.5199 & 42.5837 \\
\hline LNSS & -17.1031 & 0.9388 & -15.3757 & 1.0555 & 3.5472 & 3.7793 & $\begin{array}{c}- \\
18.7500\end{array}$ & $12 . \overline{-}$ & 1.7500 & 13.0403 & 42.6029 \\
\hline MTER & -1.5630 & 0.6407 & -8.9677 & 0.7256 & 1.3275 & 2.5464 & -3.9700 & -5.7700 & 2.4700 & 13.2144 & 42.5088 \\
\hline TERA & 6.6400 & 1.7808 & 0.7300 & 1.7808 & 0.2600 & 7.0967 & 5.6500 & 0.3900 & 0.3500 & 13.6981 & 42.6571 \\
\hline TOSS & 3.5957 & 0.9985 & -0.4689 & 1.2137 & 3.4299 & 4.0764 & 2.7600 & -0.0400 & 0.9300 & 13.6458 & 42.5472 \\
\hline
\end{tabular}

\section{COSEISMIC DISPLACEMENTS AND FAUT MODEL}

Figure 2 shows the combined horizontal (red arrows) and vertical (blue arrows) coseismic displacements for the August, 24 mainshock, with $65 \%$ error ellipses. The east, north and vertical coseismic offsets (in $\mathrm{mm}$ ) are available at the following link: ftp:/ / gpsfree.gm.ingv.it/amatrice2016/static/ CombinedGPS_Offsets_v4R.dat, where information about the original GNSS network to which each station analyzed belongs is provided. The horizontal coseismic displacements highlight a SW-NE oriented extension, in agreement with pre-seismic geodetic measurements. The stations LNSS (Leonessa) and NRCI (Norcia) moved respectively 24 and $23 \mathrm{~mm}$, toward SW whereas the stations in Ascoli Piceno (ASCC and ASC9) moved NE-ward of $~ 15 \mathrm{~mm}$.
The station that experienced the largest displacements is the one in Amatrice (AMAT), which moved in a NNW direction of $24.5 \mathrm{~mm}$, subsiding of $15 \mathrm{~mm}$. We used the estimated "consensus" displacements to infer geometric and kinematic information for the causative fault. Because of the limited number of GPS sites available, we do not attempt to invert for a heterogeneous distribution of coseismic slip, but limited this analysis to uniform slip models. To infer the geometry of the uniform slip fault we model the observed horizontal and vertical near- and far-field coseismic displacements using a rectangular dislocation in a elastic, homogeneous and isotropic half-space (Okada, 1985). In the inversion the top of the rectangular dislocation is constrained to be in the 0-5 km depth interval, the dip in the $40-70^{\circ}$ interval, the length and width in the 3-30 km and 3-15 km 
intervals, respectively and the strike is confined between 140 and $180^{\circ}$. The best-fitting fault parameters and their relative confidence intervals were found using a global optimization algorithm (Corana et al., 1987) and a Monte Carlo simulation technique (e.g., Press et al., 1992) as described in Cheloni et al. (2010). In the uniform-slip solution (Table 2) the causative fault strikes $\sim \mathrm{NW}$-SE and dips $\sim 45^{\circ}$ to the SW, with an average slip of $\sim 0.7 \mathrm{~m}$ (rake $-78^{\circ}$ ), which (using a value of $30 \mathrm{GPa}$ for rigidity) gives an es- timated seismic moment of $2.13 \times 10^{\text {sis }} \mathrm{Nm}(\mathrm{Mw}$ 6.18). The total RMS misfit value is around 2.2 $\mathrm{mm}$. Table 2 summarizes the fault parameters obtained by non-linear inversion of the coseismic displacements shown in Fig. 2. Despite the limited number of stations, the derived source model is in agreement with the mainshock focal mechanisms and the surface ruptures (EMERGEO Working Group, 2016) observed in the field (see Figure 3).

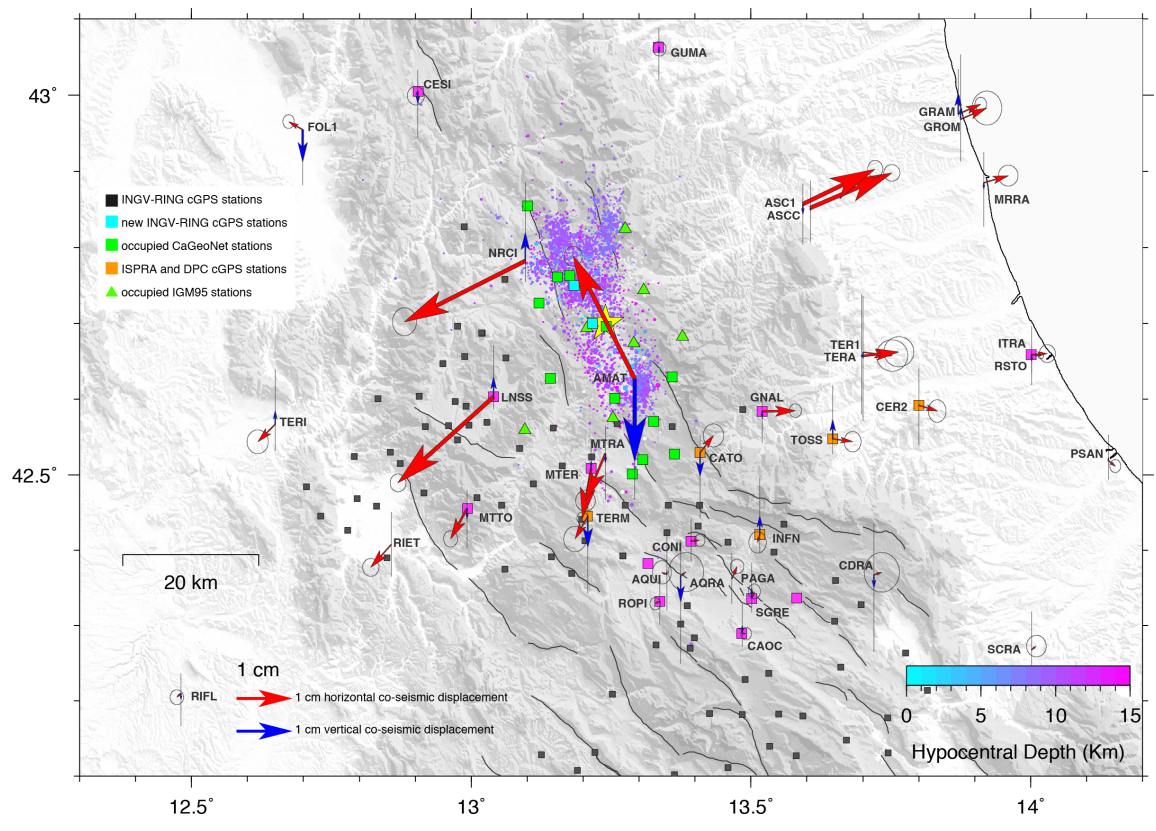

Figure 2. Horizontal (red arrows) and vertical (blue arrows) co-seismic displacements (with $68 \%$ confidence errors, shown by error ellipses and error bars in grey for the horizontal and vertical components, respectively), together with the August 24, Mw 6 mainshock (yellow star) and aftershocks (colored as a function of depth) from http://iside.rm.ingv.it. The black squares show the position of the INGV-RING stations (http://ring.gm.ingv.it). The grey squares show the position of the CaGeoNet network (Anzidei et al. 2008; Galvani et al., 2012) stations, where the green squares indicate benchmarks that have been re-occupied a few hours after the August, 24 mainshock. The green triangles indicate the position of IGM95 benchmarks (http://www.igmi.org/geodetica/) that have been occupied by ISPRA (www.isprambiente.gov.it) and DPC (Civil Protection Department) after the mainshock. The orange squares indicate continuous GPS stations managed by DPC and ISPRA. 

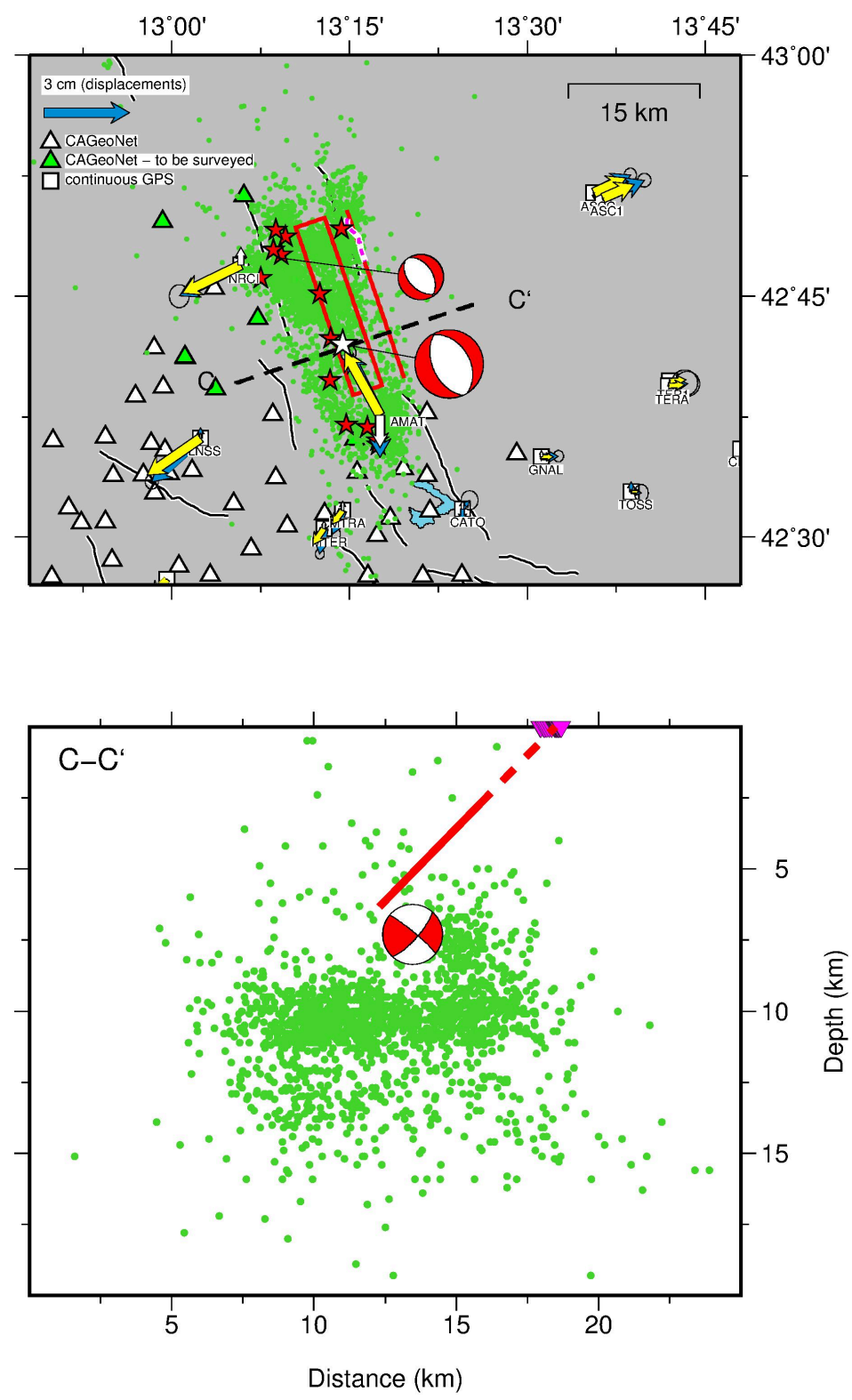

Figure 3. [Top] The cyan, yellow and white arrows show observed (cyan) coseismic displacements and modeled horizontal and vertical displacements, respectively, from the uniform slip inversion. The red stars show aftershocks with $M>4$. The red box shows the projection of the seismic fault and the red line shows its alongdip projection at the surface. [Bottom] Cross section $\left(\mathrm{C}-\mathrm{C}^{\prime}\right)$ showing the coseismic fault (continuous red line), aftershocks (green circles), focal mechanism (http://cnt.rm.ingv.it/tdmt) and surface ruptures (purple triangles). It is worth noting that the earthquakes plotted in this figure are not from a relocated seismicity catalogue, which explains the scattering. 
Table 2. Coseismic fault parameters obtained by non-linear inversion of the coseismic displacements shown in Figure 2. $C F_{x_{p}}$ Lat and $C F_{x_{p}}$ Lon indicate the longitude and latitude of the center of the top edge of the model fault. For each parameter we provide the lower and upper bounds at the 95\% confidence obtained from the Monte Carlo analysis.

\begin{tabular}{cccccccccc}
\hline $\begin{array}{c}\text { Length } \\
(\mathbf{k m})\end{array}$ & $\begin{array}{c}\text { Width } \\
\mathbf{( k m )}\end{array}$ & $\begin{array}{c}\text { Depth } \\
\mathbf{( k m )}\end{array}$ & $\begin{array}{c}\text { Dip } \\
\left({ }^{\circ}\right)\end{array}$ & $\begin{array}{c}\text { Strike } \\
\left({ }^{\circ}\right)\end{array}$ & $\begin{array}{c}\mathrm{CF}_{\text {rop }} \text { Lon } \\
\left({ }^{\circ} \mathbf{E}\right)\end{array}$ & $\begin{array}{c}\mathrm{CF}_{\text {rop }} \text { Lat } \\
\left({ }^{\circ} \mathbf{N}\right)\end{array}$ & $\begin{array}{c}\text { Slip } \\
(\mathbf{c m})\end{array}$ & $\begin{array}{c}\text { Rake } \\
\left({ }^{\circ}\right)\end{array}$ & $\begin{array}{c}\text { Mo- } \\
\text { ment } \\
(\mathbf{1 0 *} \mathbf{N m})\end{array}$ \\
\hline $20.41_{-7.07}^{99.93}$ & $5.01_{-2.01}^{4.44}$ & $2.75_{-2.06}^{3.05}$ & $45.6_{-12.6}^{10.3}$ & $161.5_{-9.3}^{13.6}$ & $13.2553_{-0.0283}^{0.0586}$ & $42.7446_{-0.0254}^{0.0366}$ & $0.695_{-12.6}^{10.3}$ & $-78.0_{-11.9}^{12.4}$ & $2.13_{-1.5}^{6.64}$ \\
\hline
\end{tabular}

\section{CONCLUSIONS}

As shown during the Emilia 2012 earthquake sequence, the availability of, even sparse, GPS stations continuously recording across moderate magnitude earthquakes can provide reliable constraints on the geometry and kinematics of the causative fault. The results shown in this work have been obtained largely exploiting data from non-geophysical networks, generally characterized by relatively lower quality data and monuments than geophysical networks, such as the INGV-RING network (INGV RING Working Group, 2016). Moreover, as for the L'Aquila 2009 sequence, the availability of a denser survey-mode geodetic network, repeatedly measured in the past to provide reliable estimates of the pre-seismic (i.e., interseismic) velocities, such as the CaGeoNet, is of fundamental importance for discriminating nearfault kinematic features as the spatial distribution of coseismic slip on the main fault and post-seismic (e.g., afterslip) deformation. Although preliminary, the results shown in this work are in agreement with indications from InSAR, earthquake focal mechanisms and surface breaks observations, which consistently suggest that the causative fault is a westdipping normal fault, activating the southwestern part of the Mnt. Vettore normal fault (e.g., Pizzi and Galadini, 2009) and the northwestern part of the Gorzano normal fault (Boncio et al., 2004). Further works will include the densification of the GPS coseismic map, including the coseismic displacements from the campaign data collected soon after the mainshock and the integration of GPS and InSAR displacements in order to solve for the variable slip distribution and the stress changes associated to this earthquake.

\section{ACKNOWLEDGMENTS}

We thank all public and private institutions that manage and distribute the GPS data used in this work, and in particular: EUREF (http://www.epncb.oma.be), Italian Space Agency (ASI: http://geodaf.mt.asi.it), Leica Geosystem for the ItaPos data (http:/ / it.smartnet-eu.com), GeoTop srl for the NetGeo data (http:/ / www.netgeo.it), Regione Umbria (http:/ / labtopo.ing.unipg.it/labtopo), Regione Abruzzo (http:/ / gnssnet.regione.abruzzo.it) and Regione Lazio (http://gnssregionelazio.dyndns.org).

\section{REFERENCES}

Anzidei, M., P. Baldi, A. Pesci, S. Del Mese, A. Esposito, A. Galvani, F. Loddo, A. Massucci and P. Cristofoletti (2008). La rete Geodetica GPS dell'Appennino centrale CAGeoNet, Quaderni di Geofisica, 54, 43 pp. with appendix of $254 \mathrm{pp}$. Istituto Nazionale di Geofisica e Vulcanologia.

Avallone et al., Preliminary coseismic dynamic displacements for the 2016 August $24 \mathrm{Mw}$ 6.0 Amatrice earthquake (central Italy) carried out from High-Rate GPS data, submitted to this issue. 
Avallone, A. et al. (2010). The RING network: improvements to a GPS velocity field in the central Mediterranean, Ann. Geophys., 53(2), 39-54, doi:10.4401/ag-4549.

Bignami, C., C. Tolomei, S. Atzori, S. Stramondo, S. Salvi, R. Castaldo, F. Casu, C. De Luca, V. De Novellis, R. Lanari, A. Pepe, S. Pepe, P. Tizzani and I. Zinno (2016). Sequenza sismica di Amatice, Risultati iniziali delle analisi interferometriche satellitari, DOI : 10.5281 / zenodo.60938.

Boncio, P., G. Lavecchia, G. Milana and B. Rozzi (2004). Seismogenesis in Central Apennines, Italy: an integrated analysis of minor earthquake sequences and structural data in the Amatrice-Campotosto area, Ann Geophys-Italy, 47(6), 1723-1742.

Cheloni, D. et al. (2010). Coseismic and initial post-seismic slip of the $2009 \mathrm{Mw} 6.3$ L'Aquila earthquake, Italy, from GPS measurements, Geophys. J. Int., 181, doi:10.1111/j.1365-246X.2010.04584.x.

Corana, A., M. Marchesi, C. Martini and S. Ridella (1987). Minimizing multimodal functions of continuous variables with the "Simulated Annealing" algorithm, ACM Trans. Math. Softw., 13, $262-280$.

D'Agostino, N. (2014). Complete seismic release of tectonic strain and earthquake recurrence in the Apennines (Italy), Geophys. Res. Lett., doi:10.1002/(ISSN)1944-8007.

Devoti R., N. D'Agostino, E. Serpelloni, G. Pietrantonio, F. Riguzzi, A. Avallone, A. Cavaliere, D. Cheloni, G. Cecere, C. D'Ambrosio, L. Falco, G. Selvaggi, M. Métois, A. Esposito, V. Sepe, A. Galvani and M. Anzidei
(2016). The Mediterranean Crustal Motion Map compiled at INGV, Ann. Geophys., under review.

Devoti, R. (2012). Combination of coseismic displacement fields: a geodetic perspective, Ann Geophys-Italy, doi:10.4401 / ag-6119.

EMERGEO Working Group (2016). The $24 \mathrm{Au}$ gust 2016 Amatrice Earthquake: Coseismic Effects, doi; 105281 / zenodo.61568.

Galvani, A., M. Anzidei, R. Devoti, E. Esposito, G. Pietrantonio, A.R. Pisani, F. Riguzzi and E. Serpelloni (2012). The interseismic velocity field of the central Apennines from a dense GPS network. Ann. Geophys. 55, 5, 2012; doi: 10.4401/ag-5634.

INGV RING Working Group (2016). Rete Integrata Nazionale GPS, doi:10.13127/ RING.

Okada, Y. (1985). Surface deformation due to tensile and shear faults in a half-space, Bull. Seismic. Soc. Am., 75, 1135 - 1154.

Pizzi, A. and F. Galadini (2009). Pre-existing cross-structures and active fault segmentation in the northern-central Apennines (Italy), Tectonophysics, 476(1-2), 304-319, doi:10.1016/j.tecto.2009.03.018.

Press, W.H., S.A. Teukolsky, W.T. Vetterling and B.P. Flannery (1992). Numerical Recipes in C: The Art of Scientific Computing, 2nd edn, Cambridge University Press, Cambridge.

Serpelloni, E. et al. (2012). GPS observations of coseismic deformation following the May 20 and 29, 2012, Emilia seismic events (northern Italy): data, analysis and preliminary models, Ann. Geophys., 55(4), doi:10.4401/ag-6168. 